\title{
WESTERN AUSTRALIA'S AGRICULTURE AND PASTORALISM IN CULTURAL AND ECOLOGICAL PERSPECTIVE
}

\author{
Henry Schapper
}

This article first appeared in Rural Society 6 (2). Rural Society is published by the Centre for Rural Social Research, Charles Sturt University, Wagga Wagga, Australia.

This article is (C) copyright, the author and the Centre for Rural Social Research. This text may be downloaded for personal use, or stored electronically, as long as no charge is made for access. The text may not be altered in any way and all hard copy or electronic versions MUST carry this header.

\section{WESTERN AUSTRALIA'S AGRICULTURE AND PASTORALISM IN CULTURAL AND ECOLOGICAL PERSPECTIVE}

Western Australia's agriculture and pastoralism may be viewed as results of interaction between systems of culture and ecology. One feature of this is summarised in two empirical observations that are the basis of this essay:

1. 'At least 1.63 million hectares (9\%) of once productive land in the agricultural regions has become salt affected . . . and is likely to rise to about 2.9 million ha. (16\%) of the cleared area by 2010' (Salinity, 1995:4).

2. '[Only] 40 percent of the rangelands [are] in good condition . . . 34 percent in fair condition [and] 26 percent in poor condition' (Wilcox and Cunningham, 1994:100. These conditions refer directly to natural plant species diversity, not necessarily to grazing productivity).

These observations are of fundamental importance to the people of WA, especially to the managers of agricultural soils and native pastoral vegetation. Consequently, they are the source of political and bureaucratic concerns for the ecological sustainability and future economic viability of the state's agricultural and pastoral industries. These concerns have been expressed in recent reports of WA parliamentary and other official committees of enquiry and task forces named below under References. Their perspective, analysis and recommendations seem largely to emerge from a conceptual framework that assumes farmers and graziers can be educated in the style of traditional agricultural extension of Australian state Departments of Agriculture, and induced by government subsidies to shift from exploitative to sustainable management.

The major inspirational background of this essay comes from a conjuncture of ideas: coevolutionary development (Norgaard, 1984), Australasian ecological history (Flannery, 1994), the influence of institutional arrangements (farm property ownership, for example) on public 
policy (Bromley, 1989), and safe minimal standards (Ciriacy-Wantrup, 1952). From this background the notions arise that farms and stations essentially are micro-ecological units of business; that use and care of soil and vegetative productivity is a function of farm and station ownership; and that responsibility for the continued sustainability of this productivity should be a legislated duty of farm and station ownership. Thus, the thrust of this essay is to propose change of the rules of farm property ownership, not to focus on new techniques of production.

\section{A Cultural and Ecological Perspective}

Less than 200 years ago, the western third of Australia - its land, inhabitants, minerals, forests and other vegetation and coastal fish - was annexed. Ownership of this part of the planet came, in effect, to be vested by alien invaders in the British Crown, which soon was to become the symbol for colonial and state government ownership. These governments disposed of their newly found resources to private citizens and companies in the form of legal title to own and farm some of the land, and licence to graze, mine, fish, and log.

Initially, all natural resources and wildlife were managed by the new settlers as stock-resources. Of course, minerals, including coal, oil and natural gas, still are, and will continue to be managed thus, until they are exhausted or there is no reason for their further extraction. The other resources increasingly are being recognised as potentially capable of sustainable management as naturally renewable (flow) resources.

However, conflicts, particularly over flow-resource use, and conservation of wildlife, became common (for example, see Calver et al, 1996). They exist between various government departments over wildlife conservation and rates of flow-resource use. Society and government often disagree over the same issues. And conflict exists between those members of society not wanting its flow resources to be managed as stock resources and the many personal and corporate legal entities who seem to act as if their legal ownership of naturally renewable resources is a right to plunder them for as long as is financially profitable.

That society's technological potential will be able to rectify the consequences of ecological disruption whenever necessity demands seems to be a widely held hypothesis concerning flowresources management. This hypothesis may rationally justify desertification, salinity and erosion, though rectification can become financially impracticable and ecologically impossible. Species extinction, of course, is a case in point.

Prominent in WA's inventory of ecological events since white settlement must be the plundering of natural resources by the alien culture. (The previous Aboriginal culture, too, modified the ecological system, largely with the firestick. 'Through its judicious use, they [Aborigines] wrested their daily meat and bread from an otherwise unforgiving land, they fought their enemies and expelled their pests' [Flannery, 1994: 217]. But this could hardly be called plundering.) The alien culture imported domesticated livestock, capital, technology and labour. The integrating principle of this culture motivated society and dominated much of its environment, as it still does. Economic profits from domestic and international markets are a major personal motive and social canon of success. Moreover, the benefits and costs of domination by this motivation continue to be distributed unequally and inequitably throughout the WA population. 
Ecological systems of coastal seas, soils, spinifex, mallee, mulga, saltbush and shrub-lands, forests and geological formations have been modified, and the natural sustainability of some of them threatened and eroded, and others destroyed by processes that we imposed. We have used these systems to generate GDP, build social and economic infrastructures, increase population, develop high mass-consumption, waste and pollution, and create endemic unemployment, and increase leisure activities. Almost all this occurred during the last century of Australia's 50,000 to 60,000 years of human occupation.

WA's tussock, mulga, saltbush and shrub ecological systems are basic to the state's pastoral grazing activities. Settled pastoralism with foreign domestic livestock converted the annual growth of edible plants that evolved during thousands of years into meat and wool for cash. It required techniques, capital, resources and markets of which the indigenous inhabitants knew nothing. For 50,000 to 60,000 thousand years, human culture in what was to become the pastoral country or rangelands was Aboriginal. This meant low population density, tribal organisation, personal and communal subsistence based on hunting and gathering, minimal labour specialisation, and slow interaction between culture and natural environment.

Aboriginal semi-nomadic culture and the natural environment coevolved with minimal disturbance of one on the other. Their results, despite having been influenced, and even dominated on occasion by perverse climatic influences of El Niño oscillations (Flannery, 1994: 81-84) and Aboriginal and naturally lighted bushfires, though profound, were gradual in comparison with those of the last 150 years, which have been rapid, labour-productive, resourceproductive, commodity-productive and resource-destructive. Adaptive interaction between Aboriginal culture and ecological systems was at possibly the lowest level of personal consumption consistent with local self-sufficient subsistence at perhaps the highest possible human population compatible with ecological sustainability. This adaption proceeded with minimal cultural and ecological interaction.

Our recent alien culture, by contrast, has dominated various ecological systems so that sometimes interaction between culture and ecology has virtually ceased. Abandonment (often from intensive use, if not always from possession) enforced by accelerated desertification in pastoral country and salinity in agricultural regions is prime evidence. White pastoral settlement, in little more than a century, has set new ecological forces in motion. The alien culture bred and multiplied sheep and cattle to gather and process the naturally growing plant material. These livestock competed with the indigenous animal wildlife. They fossicked for edible native plant growth, ingested, processed and transformed it into wool and flesh. Much of this new cultural impact between the white settlers' livestock-based economy and the ecological system, though highly productive in the short term, was unsustainable. In one century many millions of sheep and cattle grazed. Each animal, driven by hunger, with its natural mower to cut and mechanism to grind the natural vegetation, and a series of fermentation vats mounted on a four-footed hard cloven-hooved transport system, transformed native plants into marketable raw materials. The natural ecology was massively disturbed. Gathering the edible plant material, often to the extinction of individual species, simultaneously with new hard-hoof cultivation, inevitably opened the soils to the wind and water agents of erosion that are ever-present in most land systems. Additional to this new interaction was destruction caused by imported animals, 
particularly goats, donkeys, horses and rabbits which became feral. That they may be out of control exacerbates their cultural impact.

The natural ecological system that presently is exploited as 'rangeland' amounts to about 38 per cent of WA, yielding almost four per cent of gross value of WA agricultural production. 'In 1993, the Pastoral Wool Industry Task Force observed that virtually no wool pastoral properties in WA are able to generate a positive cash income at current wool prices (1993 prices) and 30\% to $60 \%$ of wool pastoral businesses will have to leave the industry' (Sustainable Development, 1996:4). As may be expected, one result is that government now spends more money on services to the pastoral industry than it collects as rent (Jennings, 1979).

The rangeland system is characterised by regular climatic wets and drys interrupted, particularly in the drier regions, by unpredictably-occurring droughts and floods of unpredictable duration that interact with low natural soil and plant productivity. Climate and soils are the basis of WA's rangeland environment and its incompatibility with western-style settlement and living. Apart from the widely scattered stations (ranches), settlements are confined to small, distancedominated centres of natural resource exploitation linked to foreign commodity markets for minerals and a little production from irrigated soils, and to small centres of government service agencies and ports. Despite what settlement there is, spatial vastness devoid of human life dominates the pastoral landscape and its sparse animal population.

Despite these features of the rangelands system, it has been financially profitable to lessees. But ecologically, many lessees have managed its natural productivity unsustainably. Government, as their landlord and administrator of the pastoral leases by which grazing rights are allocated, has, in effect, presided over productivity degradation of much of the publicly-owned pastoral country. Historically, the lessees, in effect, determined the management of the pastoral ecosystems. The government urged settlement and development. Even now, the government tends to legitimise the lessees' management for increased economic production rather than supervise it for sustainable productivity.

Encouragement of private investment in economic development has always been a high government priority. When parliaments in WA were dominated by pastoralists, the ethos of economic development favoured what, with hindsight, may be realistically perceived as plundering the rangelands. Even so, the grazing business of some lessees is financially operational for the moment only because they do not provide adequately for business asset depreciation, superannuation and children's education, for example.

Government statistics suggest that a century of ecological disturbance of the rangelands through domesticated livestock has maintained only '40 percent of the rangelands in good condition', '34 percent in fair condition' and '26 percent in poor condition', including some completely destroyed (Wilcox \& Cunningham, 1994:100). 'About 20 per cent is rated as poor condition, i.e., lacking vegetative cover' by the Environmental Protection Authority in its Annual Report 1994-1995: 11.

Can this kind of development continue? Ultimately, of course, degradation of rangeland vegetation and soils could proceed to a point of unrecoverability, namely, desertification. But before then, financial unprofitability probably will encourage, as it has in the past, 
amalgamations of pastoral businesses. Through amalgamations, the effects of falling productivity and profitability of individual pastoral businesses can be offset by an increased volume of sales from bigger (but fewer) businesses. This is a common business strategy in agriculture, commerce and industry. In pastoralism and agriculture, amalgamation is made initially in response to threats of financial loss, not to ecological unsustainability. Often, too, temporary ecological exploitation (involving soil erosion and vegetative depletion) is the managerial strategy to recover from an adverse run of seasons or spell of adverse terms of trade. (Adjustments through business amalgamation in commerce and industry, in contrast, typically involve increased unemployment and increased labour effort of the employed.)

WA's wood, mallee and heath lands characterise the ecological systems from which agricultural settlements based on broadacre cropping developed. The first requirement of arable farmers was to clear land of its natural vegetation. They soon found that financial viability required an annual cost and revenue regime that motivated them to increase farm size by clearing more land, and to make and adopt technological innovations whose financial outcome would result in net income roughly equal to those of people in comparable non-farm occupations.

The enterprise of farmers with their technical innovations has certainly been spectacular in its ecological and economic impacts. The alien agricultural culture raised the productivity of many soils, particularly through phosphate, trace elements, legumes and weed control. It also resulted in high volumes of grains, wools and meats produced and exported. Its high economic efficiency by the standards of world markets has put it in the forefront of international economic competitiveness where it still is. These developments involved on-farm adoption of specialised mechanisation and techniques of clearing, cultivating, seeding and harvesting activities; fertiliser technology; plants imported and locally bred; legume-based rotations; weed and pest control technology; and integration of livestock husbandry with cropping.

Interaction between the natural ecosystems and modern arable farming was, and still is, ecologically disruptive. Nevertheless it pays off extremely handsomely to many individual farm owners. However, this agricultural culture has degraded some soils by erosion, mechanical compaction, acidification, biological exhaustion and water repellence. But next to erosion, the most profound negative outcome of interaction between this agricultural culture and relevant ecological system is salinity of soils and streams.

Clearing the natural vegetation and substituting for it bare fallow and annual crops and pastures has disrupted the ecological system's groundwater levels. The roots of the original mallee and shrub vegetation deeply penetrate the soil and subsoil to keep groundwater and dissolved salts below the reach of roots of annual crop and pasture plants. Most larger plants of the natural vegetation transpire groundwater into the atmosphere. When clearing ends this transpiration, the groundwater, renewed by annual rainfall from salty seas, gradually rises, bringing salts to the soil surface with which few alien annual plants can cope. This salinisation of agricultural soils now has government, farmers and many other citizens calling for urgent preventive and remedial action.

Most recent estimates of WA]s salinity problem are that 'at least 1.63 million ha. (9\%) of once productive land in the agricultural region ... has become salt-affected. The prognosis is that [it] 
is likely to rise to about 2.9 million ha. (16.4\% of the cleared area) by 2010; $80 \%$ (by length) of the region's rivers and streams are seriously degraded. Salinity levels of the affected large rivers continue to increase; less than half (48\%) of the potential divertible surface water resources of the region are still fresh; more than a third (36\%) are ... no longer potable. Many rural towns ... are threatened with or are experiencing damage ... from rising saline watertables ... many [dams, soaks and bores] have been abandoned ... The agricultural region of WA has lost more species of plants and animals than any other comparable region in the world. It is projected that up to $50 \%$ of remnant vegetation on private land ... will be lost to salinity, and hence species loss will continue' (Salinity, 1995: 4).

The question is again asked, can this kind of development continue? Ultimately, of course, productivity depletion and degradation of arable agricultural soils could proceed to virtual unrecoverability, as with salinity for example. But before then, as with the rangelands, prospects of lower soil productivity and higher financial losses will encourage further amalgamations of agricultural farm businesses. This adjustment, which has proceeded for many decades, though mainly in response to economic pressures (summarised as the cost-price squeeze, for example), has not prevented all agricultural soil degradation. Nor are further amalgamations a guarantee of ecological adjustment in the future.

The cultural and ecological perspectives of WA's arable agriculture and pastoralism can be visualised figuratively as probable trends in productivity per hectare before and during white settlement of agricultural soils and pastoral vegetation.

(Figure 1 about here)

The future prosperity of pastoralism and agriculture clearly requires new relationships between our cultural and ecological systems: specifically, between economic viability and sustainable physical productivity. Almost certainly, such relationships require future policy action to be different from reviving land conservation district committees (LCDCs), and from implementing the remedies that so often are urged, particularly by farmers, to become government policy. The latest batch of farmers' recommendations include regional assessments, educational processes, models of best-practice for local governments, co-ordinated and consistent government delivery of landcare services, technical surveys in agricultural areas of hydrology and salinity, increased government support for innovative research into sustainable farming systems, increased government funds for water management in the landscape, more and better trained Landcare development officers, increased government funds to each LCDC, increased government funds for remnant vegetation protection, increased funding through federal government taxation deductions, increased government funds for farm water, and increased government funds for landcare education in schools (Landcare Review Committee, 1995: 1-7). A new proposal to protect broadacre agriculture from salinity, independent of the foregoing recommendations, is to channel the surface salt water from the agricultural landscape to mining activities in the WA goldfields (desert) region.

These recommendations are plausible. But they would probably result in increased administration and services rather than ending native vegetation degradation and soil salinity, for example. Inadvertently, too, the recommendations trivialise the situation they are intended to 
remedy. This may be inferred by comparing them with the following analysis of the microecological system that every farmer and grazier manages.

\section{Farm and Station as a Micro-ecological Unit of Business Management}

Conceptually, each profit-maximising farm and station manager is confronted with having to choose a level of production somewhere between its estimated highest possible per hectare yield and an estimated safe maximum level of depletion of soil productivity and natural grazing vegetation respectively.

In the rangelands, inputs to raise the actual level of productivity of natural vegetation to some higher level are few and limited: more fencing and water points, reduced stocking rates, better livestock husbandry and feral animal control, and more frequent burning-off. But if stocking rates are such that domestic and feral livestock consume more than the annual growth of the natural edible plants, the vegetation will deteriorate and the rangelands ultimately become desert or inedible woody shrub lands as already has occurred, particularly in arid pastoral regions.

On arable agricultural soils after clearing, the profit-maximising farm manager is confronted with the same initial basic choice. But he or she has a relatively wide range of inputs by which to maintain and raise per hectare productivity above its natural level and to restore productivity after a cropping sequence. Even so, financial costs of producing will ultimately constrain affordable yields to less than their technical maximum, though often not before the soil has become vulnerable to wind and water erosion and salinity.

For both pastoralism and arable agriculture, conceptually, there exists a level of depletion of per hectare productivity from stocking, clearing and cropping beyond which productivity may be recovered only at great expense or not at all. Thus, sustainability and profitability together require every manager to produce within the recoverability zone of productivity of his or her natural resources. Even then, 30 to 40 years after extensive clearing of arable soils, soil and stream salinity may emerge without subsequent stocking and cropping, and may require many more years to respond to remediation.

Where, it may be asked, is the margin between the recoverability and unrecoverability zones of productivity? It can be known with certainty only when it has been reached. Although not precisely predictable, it is real enough. Therefore, prudent management suggests that farm and station managers conceptualise (as many probably do) an uncertainty zone of productivity for each distinctly different part of their property. This zone would have as its lower boundary the margin between recoverability and unrecoverability. Its upper boundary would be an estimated safe maximum level of depletion of productivity below which depletion is likely to be physically unrecoverable, financially disastrous, ecologically destructive, and socially reprehensible. This conceptualisation of land-use productivity zones is shown in Figure 2.

(Figure 2 about here)

In Figure 2 per hectare productivity of Manager \#1 is shown to have fluctuated from year to year, as is normal, but always above the safe maximum level of depletion. Per hectare production 
under Manager \#2 also fluctuated annually. But sometimes it fell into the uncertainty zone, and some of the property has been eaten-out or over-burned and desertified and its productivity is in the unrecoverability zone. Parts of other properties are cropped-out and eroded. And many others, having been over-cleared, are partly salinised and perhaps beyond recovery

\section{Rights of Ownership and Management}

The initial and fundamental requirement for government's agricultural and pastoral policy is to balance maximum individual private good and maximum common public good for and from the state's farms and stations. This means that production processes that degrade presently occupied WA rangeland vegetation and arable agricultural soils should cease and henceforth should be managed to be productively sustainable in perpetuity. The implied reform of production processes is practical, and to ensure it is assumed to be one of government's fundamental responsibilities.

Absolute sovereignty over all land and its natural resources in WA resides in its citizens collectively and their government, not in the freehold rights of private ownership, nor, probably, in native title (Butt and Eagleson, 1993). This may not be in everyone's understanding of ownership. Natural as it may seem, ownership of land, for example, legally is, 'not to own but have right' (Fitzgerald, 1966: 251). In English jurisprudence, ownership 'consists in a complex of rights' (p. 246). They include the right to possess, to manage and control, to profit from, and to transfer. But 'ownership is a right of general use, not that of absolute or unlimited use' (p. 413). Thus, freehold tenure of land property derives from society as the state. And although this tenure implies exclusive use by the owner, his or her managerial autonomy is conditional on constraints, if any, placed on it by the law.

Land and natural resources are basic to everyone's existence as sources of food and water, clothing, building materials, minerals, place and environment. Access of society to these requirements takes precedence over any personal or corporate rights of natural resource ownership. Common law rights of freehold tenure (and possibly of native title) to exclude, to manage, to produce, to profit from, and to transfer to another person, ultimately are conditional on societal approval.

Society has a fundamental duty to ensure that freeholders manage soils and lessees manage the rangelands vegetation in an ecologically sustainable way. This is because sustainability is the ultimate physical basis of continuing survival and economic viability. For society to be content with ecologically unsustainable management of these resources is for it to condone a threat to its own survival. Society's responsibility and duty to require its own and private management of agricultural land and natural renewable resources to be ecologically and sustainably productive has precedence over every individual person's and corporation's agricultural and pastoral land ownership rights. WA's current and potential soil salinity crisis warrants government seriously to consider new land ownership rights.

Although government has not caused the ecological damage that private owners and lessees tolerate or have done to the property they manage, society shares responsibility for it because it tolerated such damage. This is not to imply that government should manage society's farms and 
stations. Rather, it suggests government should set and enforce standards and conditions of use of rangeland vegetation and arable agricultural soils to ensure their ecologically sustainable productivity. This is government's fundamental involvement concerning society's natural renewable resources. Sustainability requires their management always to be within their relevant recoverability zone (Figure 2).

WA has not enforced ecologically sustainable productivity on the management of its publiclyowned rangelands. Whereas the land-use managers - whether of pastoral leases or agricultural freehold - are culpable for the resource degradation they tolerate or have caused, society is culpable for allowing those who have over-cropped, over-grazed, over-cleared and are continuing to do so. The common public good seems to have been neglected by government in favour of private landed property ownership. The plea of government ignorance could once have been sustained, but certainly not at any time during this last quarter century at least

\section{What Is To Be Done}

The approach here to this question is first to specify the conditions that would maximise the individual private manager's good together with the common public good at least cost. Then appropriate measures to be implemented can be specified. The two conditions are:

- 1. Society requires, for its good and the good of the individual private farm and station manager, that everyone of them always produces within the recoverability zone of productivity (Figure 2) that is relevant for every part of his or her property, and without managerial trespass (negative impact on others).

- 2. Society determine, as part of its legal infrastructure of standards, safe maximum levels of depletion of productivity (Figure 2) for typical natural grazing vegetation and arable agricultural soils in various locations, below which the manager is in breach of a tenurial right of ownership or lease.

Briefly, for a private property society such as WA to accept overall responsibility for the ecologically sustainable productivity of its renewable natural resources, it must confer on itself and every private owner and lessee enforceable responsibility for ecologically sustainable management of his or her micro-ecological unit of production. Formal standards, and monitoring of trends toward the recoverability zone of safe maximum levels of depletion of productivity of pastoral vegetation and arable agricultural soils are required. Without such standards farm and station managers can be subjected only to opinion, and perhaps for this reason executive government is reluctant to enforce sustainable management. The absence of such standards and system of monitoring trends toward them is a gap in WA's administrative infrastructure. They, in effect, define managerial accountability, and facilitate managerial responsibility and, if necessary, its assessment in courts of law.

Formal maximum and minimum standards set by society already exist as legal guidelines for an extremely wide range of activities. They concern air and sea transport, road safety, health, building codes, vehicle loads, food, air and water quality, for example. The proposal here requires society, through its relevant scientists, to establish appropriate standards for safe maximum levels of depletion of productivity for various types of rangeland vegetation and arable 
agricultural soils. To deny these standards is for society unnecessarily to risk damage to its essential resources. Whereas the Land Act 1933 and Soil and Land Conservation Act 1945 do not specify such standards, they are implied. Suffice it to say, these Acts confer 'very substantial powers to protect and conserve the rangeland resources. Inadequate supervision and intervention by successive State Governments has been a major factor in rangeland degradation' (Sustainable Development 1995:8). The same is true of the State's agricultural lands. For government not to specify adequate standards and not to enforce managerial trends towards them is to allow legal precedence of farm and station ownership to their responsible management.

Conditions 1 and 2 require the duty of ecologically sustainable management and avoidance of managerial trespass to become legal conditions of freehold and leasehold tenures of farming and grazing properties. The rights of ownership of natural renewable resources would thus be legally extended to responsibility for their management always to ensure ecologically sustainable productivity. This implies new cultural-ecological relationships, and, possibly for the long run, a new path of coevolutionary development.

Why, it may be asked, have the requisite standards and monitoring of trends not already been established? Is it because political power of farm and station property ownership overwhelms bureaucratic rationality?

- 3. Because ownership and leasehold of every farm and station is transferred some time (by sale, testamentary disposition, gift or forfeiture), and because transfer is legalised only by state registration, transfer could be conditional on formal inspection showing that every part of the property is at or above the appropriate standard of safe maximum level of depletion of productivity (Figure 2).

- 4. In the event that inspection shows the appropriate standard of safe maximum depletion has been breached, registration of transfer would be withheld until the vendor takes societally approved remedial action.

Neither 3 nor 4 above can be fairly implemented without elapse of a sunset period (say, 5 to 10 years) of notice before inspection first becomes a legal prerequisite for registration of new ownership; and prior establishment by government of standards of safe maximum levels of depletion of productivity for each major different type of natural grazing vegetation and arable agricultural soil. The costs of these standards, like others, should be met as part of society's normal infrastructure.

The total costs of inspection of an individual property and its approval for transfer would be borne equally by the vendor, purchaser and society. Because knowledge of the results of inspection would benefit all three parties, they reasonably could be expected to share its costs. In the event of non-approval, all three still would share the initial inspection costs. The vendor, also, would either take approved action to reverse exploitative trends, or pay, as society requires, for it to be done, and for costs of its supervision and of final inspection. The vendor thus would be unable to escape his or her micro-ecological productivity responsibility. The total costs of inspection and approval most probably could be covered by a charge of 0.5 to 1.0 percent of the property's sale price. One third of this charge would be affordable by each party. 
- 5. All or a proportion of approved out-of-pocket expenses intended to be incurred by every farm and station manager for new remediation measures of deterioration would be recoverable in full from the state. This fifth part of the proposal is conditional upon and coextensive with the previous four parts. (All five are necessary to assure ending existing managerial deterioration and preventing its recurrence.)

Such approval, of its own accord, would induce virtually all farmers and graziers, who are inhibited by prospective out-of-pocket expenses, to think in specific and practical ways how they may produce entirely from within the recoverability zone (Figure 2) of their property and cease all managerial activities that impact negatively on neighbouring properties. Condition 5 also recognises the need for direct 'on-farm' expenditures, not for LCDCs and more political and bureaucratic paraphernalia.

The proposal is independent of income tax deductions and Landcare rebates. These, with their inevitable delay of payments and irrelevance to non-taxpayers, seem to be a plausible substitute for action by some farmers, graziers and politicians. Another substitute is government's benefitcost approach to long-term benefits of addressing salinity, for example. Such benefit-cost analyses often are a rationalisation to yield a desired answer, not estimates of real outcomes. The real objection to such analyses in this context is that justification of management for ecologically sustainable productivity of rangelands and arable agricultural soils, like workplace safety, clean air and clean public drinking water, for example, is not realistically assessable in benefit-cost terms. Its justification is its relevance to human survival and well-being as well as owners' profitability. Profitability is a necessary but insufficient justification for ecologically sustainable productivity.

An immediate start could be made by government to end deterioration. All government expenditure of this proposal (except for inspection, determination and monitoring of standards and assessment of each manager's intended out-of-pocket claims) would be spent directly on farm and station remediation, not on education officers and co-ordinators to generate awareness and conscience-raising among farmers and graziers. The state would accept financial responsibility only for initial out-of-pocket expenses. Subsequent recurrent expenses would be the responsibility of management as a normal recurrent cost of production. Managerial breach of relevant standards of safe maximum level of depletion of productivity, would attract societal retribution. Where pastoral holdings are too small to enable lessees to finance the necessary reduction of rate of stocking, society, as landlord, must amalgamate leases or withdraw them to extend conservation or unalienated categories of 'use'. Similarly, society must facilitate amalgamation of farms which become financially unviable and unmarketable as a result of necessary clearing bans and reduced stocking or cropping. Such adjustments, though necessary for ecological sustainability appropriately could be executed by the government's Rural Adjustment and Finance Corporation.

An advantage of full or partial recovery from the state of approved out-of pocket expenses over tax deductions and rebates is that the state would be involved directly through the approval process. Thus, government would be able effectively to inject necessary catchment and regional perspectives into intended specific individual farm and station management programs. This 
contrasts with the government's mooted legislative approach to impose a plan on private management, whereas the proposal imposes inspection at the time of intended transfer.

A minor difficulty with the proposal is that standards and trends may not be achieved on every property before the time of intended transfer. This may be dealt with by the intending vendor being granted formal release from failure to reach the requisite standards by the intending transferee obtaining formal acceptance of an approved managerial program and by its registration as a memorial on the title deeds of the property to be transferred.

Finally, money. Society must share (because of its partial culpability) the out-of-pocket expenses required by 5 above. How society does this is but another political issue of many that the state and federal governments are constantly squabbling about and resolving. Recently, the WA Government financed several extra-budget multi-million dollar programs: a High Court challenge of the federal government on Mabo; the Marks commission of inquiry about Carmen Lawrence; supplementary roads construction by a new petrol tax; and WA Inc. losses by a levy on vehicle registration and a major road tunnel in Perth. Lack of money cannot be an honest government answer to it not making an immediate and substantial start with a sustainability subsidy.

- 6. The WA Soil and Land Conservation Act would continue to apply. Its major role would be to stimulate recalcitrant managers and those who otherwise would be tempted, before intending to transfer their property, to try their luck in breaching the standard of safe maximum level of depletion of productivity

This Act would be operational (as currently) between inspections prior to registration of transfer of ownership. The Act is necessarily punitive, but irrelevant where micro-ecological productivity is sustainable. It also is irrelevant when the state fails to prosecute.

The Act does not prevent the state from giving formal public recognition to all farm and station managers whose management has been at or above the relevant societal standard for at least, say, ten consecutive years. This is something the LCDCs could do well without bothering themselves about other people's ecologically unsustainable management

\section{Discussion}

The foregoing 6-part proposal is markedly different from the intended imposition of catchment and regional planning. Alternatively, the proposal, in effect, requires that society vest in all of its farmers and graziers responsibility for ecologically sustainable management at standards and trends it sets and monitors, and without managerial trespass. It proposes this new managerial responsibility be institutionalised by legislation and reinforced by government determining safe maximum levels of depletion of productivity of pastoral vegetation and arable agricultural soils. It proposes government funding directly of approved newly intended on-farm out-of-pocket expenses to achieve society's standards of safe maximum level of depletion of productivity. And it proposes government approval of property transfers to ensure managerial compliance with society's relevant standards. 
In this proposal, the government is relieved from any pretension that it could execute plans (even with the help of local farmers) for the management of 12,000 to 15,000 farmers and graziers on a catchment or other basis. The state government, as landlord of the rangelands, with fewer than 500 lessees, already has a sorry, century-long economic and ecological record. The Soil and Land Conservation Act (soon to be amended) and the LCDCs between them are unlikely to be able to administer government catchment and regional plans as an effective strategy for ensuring ecologically sustainable land productivity. Whereas the government's Department of Agriculture (now Agriculture WA) has a very good record in agricultural extension, this was for technical education about specific innovations for practising farmers. This competence has not spilled over to farm business management advice, for which, farmers have turned to private consultants.

With the incentive of recovery of all or some out-of-pocket expenditures from the state for approved productivity activities, farmers and graziers incidentally will create a major new demand for conservation consultants, as, for different reasons 20 to 25 years ago, they initiated and still maintain a strong demand for private management consultants. Moreover, the managerial unit in WA pastoralism and arable agriculture is the station and farm respectively, not the catchment, region or local government jurisdiction. Managers and their consultants, once motivated as this proposal promises, will have incentive to avoid managerial trespass, and incentive voluntarily to integrate their management as necessary. Also, possible court action and the sanctions of the Soil and Land Conservation Act exist as fall-backs against any irresponsible management including managerial trespass.

The mooted government catchment planning (Task Force, 1996) cannot but help be a government administrative intervention into the management of individual farmers and graziers. To legislate for catchment planning most probably will create widespread resentment from managers and a shrine to bureaucratic and political failure, rather than stimulate farm and station managers into micro-ecologically sustainable productivity and cooperation to avoid managerial trespass.

Adoption of the proposal quite inadvertently would generate strong interest from credit institutions in ecologically sustainable management by their farmer and grazier clients. Transfer rights of freehold and leasehold are a major feature of collateral security for business creditworthiness. Thus, the proposal gives the creditor of every rural property business a vested interest in assessing the borrower's management in relation to society's standards of safe maximum level of depletion of productivity. Credit institutions would have a vested interest in the proposal and motivation to urge government to establish these standards, and their clients to observe them - all without government incentive or coercion.

The basic function of government in a 'free' society is to put in place a legal framework (set of rules) that aims to ensure societally acceptable citizen behaviour. But, vis a vis its natural renewable resources, society doesn't have a legal framework that imposes micro-ecological responsibility on its own departments and agencies and on farmers and graziers for their management of productivity of agricultural soils and native grazing vegetation. Nor has the government established standards of safe maximum levels of depletion of productivity against which its bureaucracy and private managers can objectively assess management practices. 
Another feature of the proposal is that it is ongoing without an army of government specialist educationists, conservation officers and co-ordinators to activate apparently recalcitrant managers and apathetic LCDCs. Also, for many people, the LCDCs are a government intrusion by ministerial appointment of farmer and grazier office-bearers throughout the rural areas of the state. Such appointments may suit politically ambitious farmers, but they also discourage some otherwise prospective members. For them, LCDCs smack of bureaucratic socialism. Besides, LCDCs are not really necessary. This proposal, in contrast, changes the rules of farm and station ownership to create a different institutional and legal framework that amounts to a new cultural paradigm concerning the management of WA's natural renewable resources. Individuals would respond to it without peer coercion from LCDCs.

Perhaps the outstandingly important consequence of the proposal is that, unlike the conventional political-farmer and political-bureaucratic recommendations, it conceivably will prevent new farm and station resource deterioration, besides terminating present exploitative practices. The failure of conventional proposals is not surprising. The question asked in the orthodox government reports and reviews of the subject is, in effect, how may the farmers and graziers be educated to rehabilitate existing deterioration. Their answer, by education, is explicit in the question. Education is quickly forgotten in the event of drought, fire, flood or adverse shift in rural terms of trade. These events often motivate managers to breach the safe maximum level of depletion of productivity, and even to impact negatively on neighbouring properties in the hope of financial survival.

The bureaucracies (chiefly Agriculture WA) seem unable to ask other questions and therefore have no mechanism to generate solutions that don't focus on traditional extension. Government reports appear to have done little more than promote government administration (see, for example, Task Force 1996) and further bureaucratic paper-work: more surveys, assessments, audits and reports; more committees and task forces; and political travel junkets. For this proposal, the implicit question is, what are the conditions under which farmers and station managers would immediately begin to manage their property in accordance with government standards thereby to assure society of sustainable productivity? This question has yet to be asked by the government's legislators, executive and relevant bureaucracies. From the perspective of this essay, the briefest possible answer appears to be:

- Management to ensure government determined standards of ecologically sustainable productivity must be a legally formal responsibility of farm and station ownership.

- A government sustainability subsidy to farmers and graziers must be paid to induce their compliance to relevant government determined productivity standards.

- Government inspection always must be made at time of intended property transfer (at least) to confirm compliance.

- Delay of transfer by government must be effected to enforce compliance, if necessary.

\section{Conclusion}

This proposal seems able to divert WA's pastoralism and arable agricultural activities from its current largely negative interaction with its ecological systems. The operational conditions for this diversion require it to be motivational, institutional and innovative. These describe the 6-part 
proposal. This is far more than a marginal modification within the existing culture, like peppingup the LCDCs, administrative catchment planning, increasing tax allowances, surveys and so on, as have been proposed almost ad nauseam.

The proposal requires new rules and institutional responsibilities without eroding basic private property rights and without government imposing on farmers and graziers administrative plans that it almost certainly will be unable to enforce. But a new managerial responsibility exercised by farmers and graziers is necessary. It imposes a new condition on farm and station ownership and requires society to meet approved out-of-pocket expenses for sustainable productivity practices. The proposal would set in motion new positive interactions between ecology and agricultural and pastoral cultures which may be the start of a new coevolutionary path along which society, farmers and graziers harmonise their ecological and economic activities.

The proposal here is a practical way through which the state could bring all managers and itself to accept full responsibility for the agricultural and pastoral property they manage. The proposal would effectively assure society and managers that natural renewable resources are no longer plundered, but managed simultaneously with the profit calculus and ecological productivity in perpetuity. A truly responsible government in this context would ensure as a matter of urgency that productivity management of natural agricultural and pastoral resources is micro-ecologically sustainable. This essay has outlined how this may be achieved in accordance with WA's political ethos, operational capacity and probably at least cost.

Nothing said here implies failure to recognise or reluctance to acknowledge that the productivity of many farming and some grazing properties has long been entirely in the recoverability zone of productivity (Figure 2) and without managerial trespass. Many, if not all of the managers of these farm and station properties, in effect, have accepted, from their own conceptual framework, economic viability within the constraints of responsibility for ecologically sustainable productivity of the property they own, and without managerial trespass on their neighbours

\section{Note}

The essence of the proposal first appeared as Schapper, H. P. 1990. 'Challenge to National Land Conservation Policy', Aust J Soil and Water Cons, 3(2):4-8.

I gratefully acknowledge thoughtful responses to an earlier draft of this essay from Mary and Jim Frith, Elizabeth Kington, Graeme Robertson, Beth Schultz, David Wilcox and anonymous referees.

\section{References}

Butt, P.J. and Eagleson, R. 1993. Mabo: what the High Court said. Federation Press: Leichhardt, NSW. 
Calver, M.C., Hobbs, R.J., Horwitz, P. \& Main, A.R. 1996. 'Science, principles and forest management: a response to Abbott and Christensen'. Australian Forestry 59(1):1-6.

Ciriacy-Wantrup, S. von. 1952. Resource Conservation: Economics and Politics. Uni of California Press. Berkeley.

Bromley, D.W. 1989. Economic Interests and Institutions. Blackwell: New York.

Fitzgerald, P.J. 1966. Salmond on Jurisprudence. 12th. Edition. Sweet \& Maxwell: London

Flannery, T.F. 1994. The Future Eaters: an ecological history of the Australasian lands and people. Reed: Melbourne.

House, M.G. 1991. Select Committee into Land Conservation. WA Govt Printer, Perth

Jennings, B.G. 1979. The Present and Future Pastoral Industry of Western Australia. Lands Department, Perth.

Landcare Review Committee. 1995. A Review of Landcare in Western Australia. Agriculture WA, Perth

Managing the Rangelands. 1995. Government of Western Australia Policy Statement. Perth.

Norgaard, R.B. 1984. 'Coevolutionary Development Potential'. Land Economics 60(2)160-171

Salinity: A Recommended Strategy for Western Australia. 1995. Soil and Land Conservation Council of Western Australia

Sustainable Development in the Rangelands of Western Australia: A Positive Statement. 1996. Environment Protection Authority, Perth.

Task Force. 1996. Review of Natural Resource Management and Viability of Agriculture of Western Australia: A Discussion Document. Information Services, Agriculture WA. Western Australia.

Wilcox, D.G. \& Cunningham G.M. 1994. 'Economic and Ecological Sustainability of Current Land Use in Australia's Rangelands'. Occasional Paper Series 06/93: 87-171 In R\&D for Sustainable Use and Management of Australia's Rangelands.

\section{About the author}

Henry P Schapper is Honorary Research Fellow at the University of Western Australia. 
Maintained by Kate Roberts

Email: ilws@csu.edu.au

Last update 30 January 2008

Copyright CRSR 2002 